\title{
Discours
}

Revue de linguistique, psycholinguistique et

informatique. A journal of linguistics, psycholinguistics

and computational linguistics

$4 \mid 2009$

Linearization and Segmentation in Discourse

\section{Linearization and Segmentation in Discourse: Introduction to the Special Issue}

Liesbeth Degand, Cathrine Fabricius-Hansen and Wiebke Ramm

\author{
OpenEdition \\ Journals \\ Electronic version \\ URL: http://journals.openedition.org/discours/7292 \\ DOI: $10.4000 /$ discours.7292 \\ ISSN: $1963-1723$ \\ Publisher: \\ Laboratoire LATTICE, Presses universitaires de Caen
}

\section{Electronic reference}

Liesbeth Degand, Cathrine Fabricius-Hansen and Wiebke Ramm, «Linearization and Segmentation in Discourse: Introduction to the Special Issue », Discours [Online], 4 | 2009, Online since 30 June 2009, connection on 19 April 2019. URL : http://journals.openedition.org/discours/7292 ; DOI : 10.4000/ discours.7292

\section{(c) (i) (9)}

Discours est mis à disposition selon les termes de la licence Creative Commons Attribution - Pas d'Utilisation Commerciale - Pas de Modification 4.0 International. 


\title{
Linearization and Segmentation in Discourse: Introduction to the Special Issue
}

\author{
Liesbeth Degand ${ }^{1}$, Cathrine Fabricius-Hansen ${ }^{2}$, Wiebke Ramm ${ }^{2}$ \\ ${ }^{1}$ Université catholique de Louvain, ${ }^{2}$ University of Oslo
}

1 Like other forms of communication, language is inseparably tied to some kind of linearsequential presentation, due to the linear-sequential nature of the media it operates on. Linearization in its turn presupposes segmentation, i.e. decisions concerning the size and type of units to be brought into a sequential order at various levels. In written and spoken language, for example, it has to be decided whether a piece of information can and should be realized as a word, a phrase, a clause, a (complex) sentence or even as a sentence sequence or paragraph. Additionally, the relevant units have to be arranged in a certain order that is determined - in part, at least - by the rules of grammar but also - at higher levels of discourse - by other principles. Identifying and defining such principles is a crucial issue in discourse studies.

2 "Linearization and Segmentation in Discourse" was the theme of the 2008 edition of Multidisciplinary Approaches to Discourse (MAD), a workshop series which has the aim to bring together researchers from different linguistic disciplines to exchange information and learn from each other on a common topic of investigation. The workshop was organized by Cathrine Fabricius-Hansen and Wiebke Ramm (University of Oslo) (http://www.hf.uio.no/ilos/forskning/konferanser/mad08/). This special issue brings together a number of selected and revised papers that were presented at this workshop. A preliminary version of the articles appeared in the proceedings of the workshop (Ramm \& FabriciusHansen 2008).

3 The topics addressed in the papers collected in this issue cover a broad spectrum of methodologies (e.g., cognitive and psycholinguistics, corpus linguistics, discourse analysis) and research interests/objectives. The issue of (basic) discourse units and segmentation is discussed in the papers by Degand \& Simon and Ho-Dac \& Péry-Woodley. The mapping of non-linear structures onto linear linguistic structures is taken up in Myachykov et al. Certain types of discourse relations and their linguistic realization and signaling by connectives are central issues in the papers by Ho-Dac \& Péry-Woodley (temporal relations) and Stukker \& Sanders (causal relations). Questions of linearization and segmentation in task management and problem solving are taken up in Falzon's contribution. The methods of Discourse Analysis are deployed in the papers by Falzon and Zima et al. - albeit in very different dialogue scenarios, namely air traffic control and parliamentary debates. The paper by Zima et al. can also be grouped together with Degand \& Simon, since these papers argue for some form of multi-layered approach to discourse (representation).

$4 \quad$ In their paper "On identifying basic discourse units in speech", Liesbeth Degand and Anne Catherine Simon tackle the issue of defining and identifying discourse units in (spoken) language. In their view the basic discourse unit is a multi-dimensional unit that results from mapping prosodic and syntactic (dependency) segments onto one another. The authors embed this methodological proposal in a theoretical discussion on the function of such units in discourse interpretation. This issue of discourse segmentation is analyzed further in the contribution by Lydia-Mai Ho-Dac and Marie-Paule Péry-Woodley on " A data-driven study of temporal adverbials as discourse segmentation markers", in which they tackle the use of (sentence initial) temporal adverbials as discourse segmentation markers. Through a combination of qualitative and quantitative analyses of a large diversified tagged corpus, the authors show that temporal adverbials can signal discontinuity in discourse, but only in specific configurations related to their position in the document structure and/or the type of 
grammatical subject of their host sentence. In other words, they cannot be considered as segmentation markers in their own right.

5 In his article "Discourse segmentation and the management of multiple tasks in single episodes of air traffic controller-pilot spoken radio communication" Paul Falzon concentrates on discourse segmentation in air traffic control dialogues. Taking a conversation analytic standpoint, he analyzes transmission design and sequential organization of multiple discourse tasks in radio-mediated pilot-controller spoken communication. From the analysis it emerges that in addition to the serial type of sequential organizations described by Schegloff, there exists an alternative form of organisation that enables tasks to be managed in a quasi-parallel manner, and which affords controllers and pilots a number of practical advantages in the conduct of their radio-mediated service encounters. Within the area of parliamentary debates, Elisabeth Zima, Geert Brône, Kurt Feyaerts, and Paul Sambre follow a comparable view on conversation as a joint activity. Their contribution "The activation of resonance in French parliamentary debates" starts from the observation that speakers tend to align their utterances with those of their interlocutors by reusing and reinterpreting the co-present linguistic material. More specifically, they focus on the activation of resonance, i.e. cross-turn parallelisms and structural mapping relations between speakers' utterances. The authors demonstrate that resonance can be activated both through explicit repetition of linguistic form and implicit echoing of semantic and pragmatic meaning. With regard to the specific discourse genre of parliamentary debates, they argue that parallelisms at all levels of linguistic organization are witti(ng)ly exploited to serve dissociative pragmatic purposes in negotiating socio-political positions and power relations.

6 This special issue closes with two more cognitively oriented papers. The paper by Myachkov, Garrod and Scheepers, "Attention and syntax in sentence production: A critical review" is concerned with the relation between changing attentional states in visual perception, on the one hand, and syntactic organization in language production, on the other hand. In particular, they explore the evidence for a regular link between the speaker's choice of sentential structure and the distribution of the speaker's attention to the event's referents, including the interaction between attentional priming and other priming effects. Still another perspective on discourse structure is taken by Ninke Stukker and Ted Sanders. In their paper "Another('s) perspective on subjectivity in causal connectives" they focus on causal connectives as categorization devices of linguistic structures with reference to the cognitively basic concept of subjectivity. The authors discuss a model of analysis that contains multiple operationalizations of subjectivity and distinguishes between different levels of complexity. They interpret different usage patterns of causal connectives in terms of prototypical vs. non-prototypical instantiations of the connectives' inherent meanings.

7 The present collection of papers reflects the discourse-oriented interdisciplinary profile of the $M A D$ workshop series as well as the aims and scope of the e-journal Discours. We hope the variety of linguistic views on aspects of linearization and segmentation in discourse unfolded in this special issue will inspire the reader and contribute to a fruitful exchange between linguistic disciplines. A final word of thanks is due to the reviewers who accepted to critically comment on an earlier version of the papers, as well as to the editors of Discours who gave us the opportunity to publish in this journal.

\section{References}

Ramm, W. \& C. Fabricius-Hansen (eds.). 2008. Linearisation and Segmentation in Discourse. Multidisciplinary Approaches to Discourse 2008 (MAD 08), Feb 20-23 2008, Lysebu, Oslo, Norway. 
Oslo: Department of Literature, Area Studies and European Languages, University of Oslo. URL: http://www.hf.uio.no/ilos/forskning/konferanser/mad08/proceedings.html

\section{To quote this paper :}

e-reference: Liesbeth Degand, Cathrine Fabricius-Hansen and Wiebke Ramm, Linearization and Segmentation in Discourse: Introduction to the Special Issue, Discours, 4| 2009, [En ligne], mis en ligne le 30 juin 2009. URL : http://discours.revues.org/index7292.html. 